Research Article

\title{
Theory and Implementation of No-Joint Wire Rope Spatial Geometry Modeling
}

\author{
Wu Zhang $\mathbb{D}^{1,2}$ Xinqian Zhang $\mathbb{D}^{1},{ }^{1}$ Chuanwei Zhang $\mathbb{D D}^{1}$ and Jiafu Zhang $\mathbb{D}^{1}$ \\ ${ }^{1}$ School of Mechanical and Engineering, Xi'an University of Science and Technology, Xi'an 710054, China \\ ${ }^{2}$ The State Key Laboratory of Mechanical Transmissions, Chongqing University, Chongqing 400044, China \\ Correspondence should be addressed to Xinqian Zhang; 359388891@qq.com
}

Received 25 April 2019; Revised 11 August 2019; Accepted 17 September 2019; Published 21 October 2019

Academic Editor: Ali Ramazani

Copyright (c) 2019 Wu Zhang et al. This is an open access article distributed under the Creative Commons Attribution License, which permits unrestricted use, distribution, and reproduction in any medium, provided the original work is properly cited.

This paper takes a cross section of $6 \times 7+$ IWS wire rope as an example to complete the studies on a method of geometric modeling for no-joint wire rope and implementation of a 3D solid model. Frenet-Serret frame theory establishes three types of Frenet-Serret frame, which are double-helix winding straight line, single-helix winding arc, and double-helix winding arc, and it allows derivation of eight types of center line equation of wire. This paper has ascertained tangent condition of center lines of steel wires with the same name between arc and straight-line wire rope and closed condition of no-joint wire rope. It has been concluded that the length of steel wire must be an integer multiple of its lay pitch either in arc wire rope or in straight-line wire rope, and the name of wires in each wire rope must be consistent at the same time. Finally, using Pro/ENGINEER Wildfire 5.0 software generates a 3D solid model of no-joint wire rope.

\section{Introduction}

No-joint wire rope (Figure 1) has unique advantages in engineering applications. It is convenient to connect the weight to hoisting equipment, it does not easily slide or fracture, and it has more carrying capacity than ordinary wire rope (Figure 2).

For no-joint wire rope that is closed into a ring, its production process is more complex and the cost is higher than for ordinary wire rope. No-joint wire rope is often used in transmission machinery; for example, the wire ropecontinuously variable transmission (WR-CVT) [1], which uses no-joint wire ropes instead of steel bands, is a typical application. A transmission system using no-joint wire rope is shown in Figure 3.

No-joint wire rope is different from the ordinary wire rope. Its closed condition of each steel wire should be considered in the process of geometric modeling. Thus, it is affected by lay angle, helix angle, lay pitch, and so on, and its modeling is difficult. At present, there are three main theories for wire rope modeling: matrix transformation theory [2], Frenet-Serret frame theory [3, 4], and enveloping surface theory [5]. The model shape mainly concentrates in the straight wire rope and arc wire rope, but there are a few studies on the modeling of no-joint wire rope. In 2000, Nawrocki and Labrosse [6] established a simple straightstranded wire rope model and analyzed the reliability under axial loads and bending compound loads. Later, Judge et al. [7] established the multilayer single-twist wire rope model to study the complex mechanical behavior among steel wires. Erdonmez and Imrak established the model of straight wire rope with independent wire rope core [8], and three years later, the recurrence formula of $n$-tuple helix of the center line of straight round wire rope [9] was deduced. In 2012, Eva Stanová [10] used Pro/ENGINEER Wildfire 5.0 (Pro/E) software to generate the $n_{0}+\left(2 n_{0}+4\right)+n_{2}$ straight wire rope model with approximate ellipse section. Two years later, the author worked with Fedorko et al. [11] to deduce a $(3+9)$ and $(3+9+15)$ mathematical model of wire rope with a triangular section and accurately calculate the solid model of double-layered triangular steel wire rope. Both Ma et al. [12] and $\mathrm{Wu}$ et al. [13] completed the modeling of arc wire rope based on Frenet-Serret frame theory. In order to correctly analyze the mechanical characteristics of multiple 


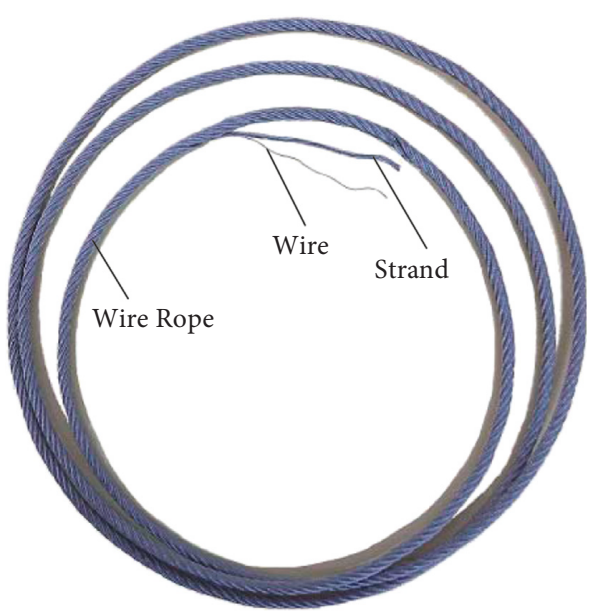

Figure 1: No-joint wire.

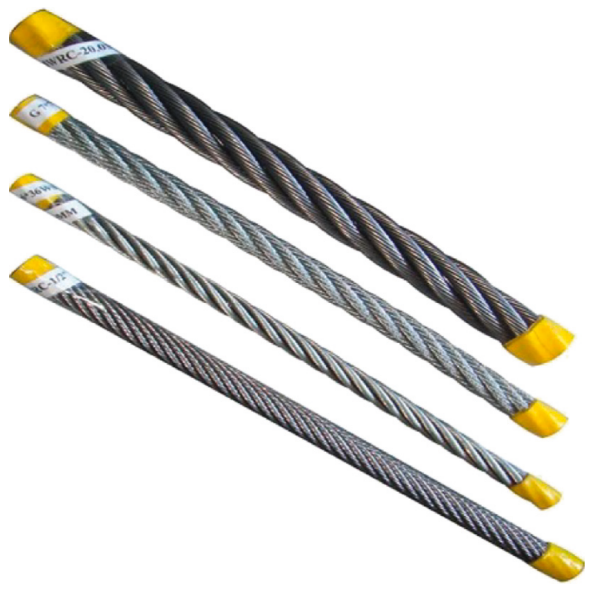

Figure 2: Ordinary wire rope.

superposition of wire rope in groove in mine hoisting, Peng et al. [14] simplified the multiple superposition of wire rope into the superposition of no-joint wire ropes.

The main purpose of wire rope geometric modeling is to facilitate the simulation of the mechanical properties and friction-wear characteristics of wire ropes under different conditions. Zhou and Tian [15] has established a finite-element model of linear single-twist wire rope to calculate its pitch length according to Timoshenko beam theory. The calculation results show that both tension and bending deformation are very close to calculation results of the Costello theory, which verifies the correctness and accuracy of the model. Stanova et al. [16] took the linear single-twist wire rope model with multiple layers as the research object and used the finite-element method to study its tensile mechanical properties. Elata et al. [17] estimated the overall mechanical properties of the wire rope by constructing a wire rope model with independent wire rope core. Páczelt and Beleznai [18] have developed a finite-element program that takes nonlinear contact, Poisson effect, friction, and wear into account, and the program can analyze the small displacement and deformation of wire ropes under a variety of loads, including stretching, torsion, and bending.
Cruzado et al. [19], based on finite-element code, performed three studies on steel wire, which investigated the area of wear scar, depth of wear scar, and volume of wear scar, and the results showed that the error could be controlled within 10\%. Two years later, Cruzado et al. [20] also carried out the wear scar prediction with a cross-angle for $15^{\circ}, 45^{\circ}$, and $60^{\circ}$, and the simulation wear scar size and experimental results are basically consistent. At the same time, Wang et al. [21], according to Archard wear theory, analyzed the influence of different intersection angles on the fretting wear depth of steel wire, and the predicted fretting wear depth is in good agreement with the experimental results. Leonard et al. [22] used microscopes and high-speed cameras to record videos and images of contact position, and the experimental device can study the fretting wear among various contact surfaces.

Based on the aforementioned research, the geometric modeling of no-joint wire rope will be carried out in this paper. The focus will be on analyzing and implementing the closed condition of no-joint wire rope and the tangent condition between straight wire rope and arc wire rope. Using Frenet-Serret frame theory, we can deduce the center line equation of straight wire rope and arc wire rope and also set up the coordinate system on different rope segments to solve the wire tangent problem. Finally, Pro/E software is used to generate a $3 \mathrm{D}$ solid model of no-joint wire rope of transmission. This study not only lays the foundation for the analysis of the dynamic performance of no-joint wire rope but also provides the theory and method for the wire rope modeling of other shapes.

\section{Basic Structure of No-Joint Wire Rope}

2.1. Basic Assumptions. This paper takes a cross section of $6 \times 7+$ IWS wire rope on right-hand Lang's lay as an example and establishes a geometric model of no-joint wire rope, collectively referred to as NJ-6 $\times 7+$ IWS. The establishment of this model is also based on the following assumptions:

(a) Ignoring the slight deformation of no-joint wire rope in the process of winding and bending, it is assumed that the cross section of each wire is circular

(b) Ignoring the small changes in helix angle of strand and helix angle of wire rope, which are caused by the production process, it is assumed that these helix angles remain constant in the wire rope

(c) It is assumed that the straight-line wire rope and the arc wire rope are in the same plane in the transmission process of the no-joint wire rope

2.2. Structure Analysis of NJ-6 $\times 7+I W S$. The structure of NJ-6 $67+$ IWS is shown in Figure 4. Helix angle and lay pitch of strand are $\alpha$ and $d_{1}$, helix angle, and lay pitch of wire rope are $\beta$ and $d_{1}^{\prime}$, and all wires are round wires with radius $r$. Wire exists in three shapes in the rope. The shape of CC is straight line or arc. The shapes of CS and OC are single-helix winding CC, and their helical radiuses are $r_{1}$ and $r_{2}$. The shape of OS is double-helix winding OC and its helical 


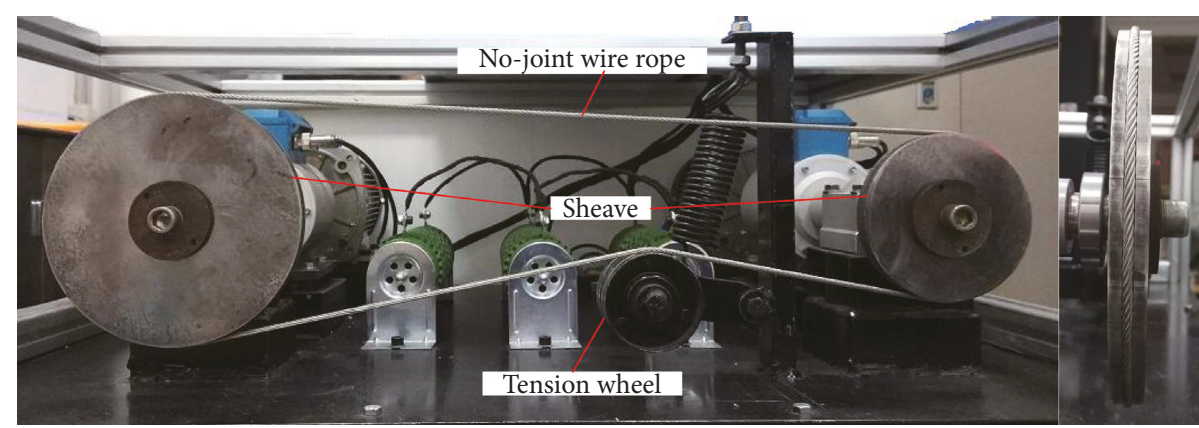

FIGURE 3: Transmission system using no-joint wire rope.

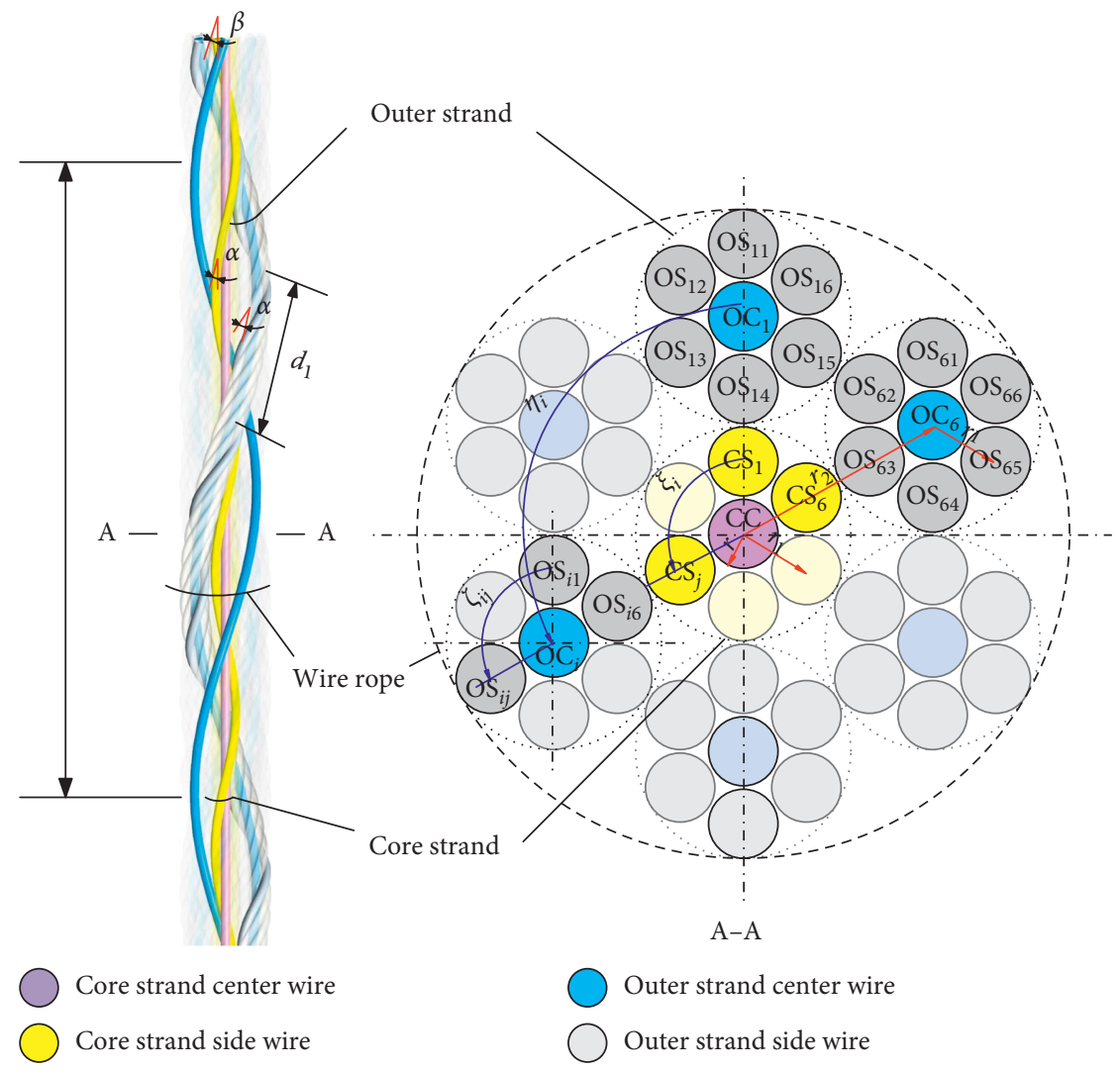

FIgURE 4: Structure of NJ-6 $6 \times 7+$ IWS.

radius is also $r_{1}$. The wire is evenly distributed around each winding center. " $\eta_{i}=(i-1) 60$ " indicates $\mathrm{OC}_{i}$ initial phase, and " $i$ " is strand number, $i=1,2, \ldots, 6$. " $\xi_{j}=(j-1) 60^{\circ}$ " indicates $\mathrm{CS}_{j}$ initial phase, and " $j$ ” is side wire number, $j=1$, $2, \ldots, 6$. " $\xi_{i j}=(j-1) 60^{\circ}$ " indicates OS $_{i j}$ initial phase, and " $i$ " and " $j$ " have the same meaning as stated previously.

\section{Frenet-Serret Frame Theory in No-Joint Wire Rope}

3.1. Frenet-Serret Frame. As shown in Figure 5, there is a curve $\mathbf{h}(\gamma)=(x(\gamma), y(\gamma), z(\gamma))$ in a Cartesian coordinate system $(O: x, y, z)$, and $\gamma$ is a function argument. There is a moving point $P$ on the curve, and $\mathbf{N}, \mathbf{B}$, and T are the point's normal vector, binormal vector, and tangent vector. The

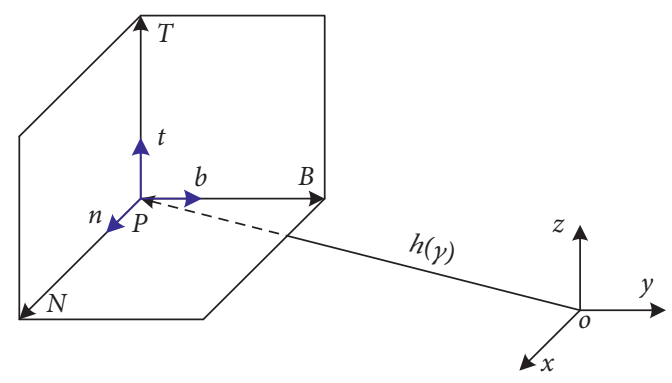

FIGURE 5: Frenet-Serret frame.

local coordinate system $\mathbf{n}-\mathbf{b}-\mathbf{t}$ composed of the unit vectors $\mathbf{n}, \mathbf{b}$, and $\mathbf{t}$ corresponding to the $\mathbf{N}, \mathbf{B}$, and $\mathbf{T}$ is called a Frenet-Serret frame. The calculation formulas are as follows: 


$$
\left\{\begin{array}{l}
\mathbf{n}=\frac{\mathbf{h}(\ddot{\gamma})}{\|\mathbf{h}(\ddot{\gamma})\|}, \\
\mathbf{b}=\mathbf{t} \times \mathbf{n}, \\
\mathbf{t}=\frac{\mathbf{h}(\dot{\gamma})}{\|\mathbf{h}(\dot{\gamma})\|} .
\end{array}\right.
$$

3.2. Application of the Frame in the Calculation of Arc Wire Rope. The no-joint wire rope is divided into arc segment and straight-line segment in the transmission process, so it is necessary to calculate the frame of each segment separately, and the calculation method of arc segment is shown in Figure 6.

The single-helix winding arc is calculated according to the following method, taking CS as an example. Firstly, the frame $\mathbf{n}_{1}-\mathbf{b}_{1}-\mathbf{t}_{1}$ is established on the center line of as the local coordinate, and $\mathbf{h}_{1}$, the vector form of CS center line in the local coordinate, is written out, secondly through the relationship between the coordinate $(O: x, y, z)$, which is at the center of the arc, and the frame $\mathbf{n}_{1}-\mathbf{b}_{1}-\mathbf{t}_{1}$ transform vector $\mathbf{h}_{1}$ into $(O: x, y, z)$ to get the vector expression of $\mathbf{h}_{1}$ in $(O: x, y, z)$. Finally, take $\mathbf{H}_{0}$, the vector form of CC, add the result of the preceding transformation, and $\mathbf{H}_{1}$, the vector form of CS centerline in coordinate $(O: x, y, z)$, is obtained:

$$
\mathbf{H}_{1}=\mathbf{H}_{0}+\mathbf{h}_{1}\left(\begin{array}{lll}
\mathbf{n}_{1} & \mathbf{b}_{1} & \mathbf{t}_{1}
\end{array}\right)^{\mathrm{T}} .
$$

The double-helix winding arc is OS, and the calculation method is as follows: OS winds OC, so $\mathbf{n}_{2}-\mathbf{b}_{2}-\mathbf{t}_{2}$ is established on the center line of $\mathrm{OC}$ as a local coordinate system. However, because the shape of this wire rope is an arc, in order to ensure that the OS always winds the center line of the OC, it is necessary to use matrix $\mathbf{T}$ to transform the local coordinate system. The latter step is similar to calculation of a single helix, so $\mathbf{H}_{2}$, the vector expression of the OS centerline in the coordinate $(O: x, y, z)$, is obtained:

$$
\mathbf{H}_{2}=\mathbf{H}_{1}^{\prime}+\mathbf{h}_{2} \mathbf{T}\left(\begin{array}{lll}
\mathbf{n}_{2} & \mathbf{b}_{2} & \mathbf{t}_{2}
\end{array}\right)^{\mathrm{T}} \text {, }
$$

where $\mathbf{H}_{1}^{\prime}$ is the vector form of center line of OC in coordinate $(O: x, y, z)$, and $\mathbf{h}_{2}$ is the vector form of center line of OS in the frame $\mathbf{n}_{2}-\mathbf{b}_{2}-\mathbf{t}_{2}$.

\subsection{Application of the Frame in the Calculation of Straight} Wire Rope. The single-helix winding straight line is OS and OC, which can be written directly. The double helix is OS and needs to be deduced by using the frame, as shown in Figure 7.

The coordinate $(O: x, y, z)$ is established at the starting position of the center line of CC, and the frame $\mathbf{n}_{\mathrm{b}}-\mathbf{b}_{\mathrm{b}}-\mathbf{t}_{\mathrm{b}}$ is established on the center line of $\mathrm{OC}$ as the local coordinate system. The vector of center line of OS in the $\mathbf{n}_{\mathrm{b}}-\mathbf{b}_{\mathrm{b}}-\mathbf{t}_{\mathrm{b}}$ is $\mathbf{l}_{2}$, and then transform $\mathbf{l}_{2}$ into the coordinate $(O: x, y, z)$. Finally, by adding $\mathbf{L}_{1}^{\prime}$, the vector form of center line of OC in the coordinate system $(O: x, y, z)$, to the preceding transformation result for $\mathbf{l}_{2}, \mathrm{~L}_{2}$, the vector center line of OS in the coordinate $(O: x, y, z)$, is obtained:

$$
\mathbf{L}_{2}=\mathbf{L}_{1}^{\prime}+\mathbf{l}_{2}\left(\begin{array}{lll}
\mathbf{n}_{\mathrm{b}} & \mathbf{b}_{\mathrm{b}} & \mathbf{t}_{\mathrm{b}}
\end{array}\right)^{\mathrm{T}} .
$$

\section{Center Line Equations of Wire in NJ- $6 \times 7+$ IWS}

4.1. Tangent and Closed Conditions of Wire. The arc and the straight line are tangent in the transmission process of nojoint wire rope. Therefore, it is necessary to consider the tangential problem between steel wires in each rope segment when deducing the center line equations of wire. When the end faces of the corresponding wires in the arc and the straight line coincide and their tangents are the same, the arc and the straight-line wire rope are tangent. Based on this condition, set up the coordinate system as shown in Figure 8.

The global coordinate systems of Arc I and Arc II is $\left(O_{1}\right.$ : $\left.x_{1}, y_{1}, z_{1}\right)$ and $\left(\mathrm{O}_{3}: x_{3}, y_{3}, z_{3}\right)$, located at the center of each arc. The global coordinate systems of Line I and Line II are $\left(\mathrm{O}_{2}\right.$ : $\left.x_{2}, y_{2}, z_{2}\right)$ and $\left(O_{4}: x_{4}, y_{4}, z_{4}\right)$, which are, respectively, located at the tangent points of Arc I and Line I and Line II, and the direction of the $y$-axis is the same as the tangent direction of Arc I at the endpoint. $R_{n}$ and $\omega_{n}(n=1,2)$ are, respectively, the radius of arc and the rotation angle.

The closed conditions, in essence, are to control the position of the end face of the wire and make the end section of each wire coincide with the starting section of the next connected wire, so as to achieve the purpose of closing the wire rope.

According to the structural analysis, there are two types of wire winding ways, as shown in Figures 9 and 10. Let the length of CC be $S_{m n}$ ( $m$ indicates shape of wire rope when " $m=1$ " is the arc and " $m=2$ " is the straight line; $n$ is the number of wire rope segment, $n=1,2) . S_{1 n}=R_{n} \omega_{n}$, $S_{2 n}=L \cos \Delta$, and derive the winding angles $\theta_{m n}$ of CS, $\varphi_{m n}$ of OC, and $\psi_{m n}$ of OS as follows:

$$
\begin{aligned}
& \theta_{m n}=\left(\frac{S_{m n}}{d_{1}}\right) \times 2 \pi, \\
& \phi_{m n}=\left(\frac{S_{m n}}{d_{1}^{\prime}}\right) \times 2 \pi, \\
& \psi_{m n}=\left(\frac{S_{m n}}{d_{1} \cos \beta}\right) \times 2 \pi .
\end{aligned}
$$

When the coefficient before $2 \pi$ is rounded, the wires will be winded around an integer multiple of their lay pitch, and all wire rope segments are closed.

4.2. Equations of Center Line of CC. The shapes of CC center line in arc wire rope and straight-line wire rope are arc and straight line, listing their equations directly. The equations of Arc I and Arc II are as follows:

$$
\left\{\begin{array}{l}
x\left(\omega_{n}\right)=0, \\
y\left(\omega_{n}\right)=R_{n} \cos \omega_{n}, \\
z\left(\omega_{n}\right)=R_{n} \sin \omega_{n},
\end{array}\right.
$$

where $\omega_{1} \in[\pi / 2+\Delta, 3 \pi / 2-\Delta]$ and $\omega_{2} \in[-(\pi / 2)-\Delta$, $\pi / 2+\Delta]$.

The equations of Line I and Line II are as follows: 


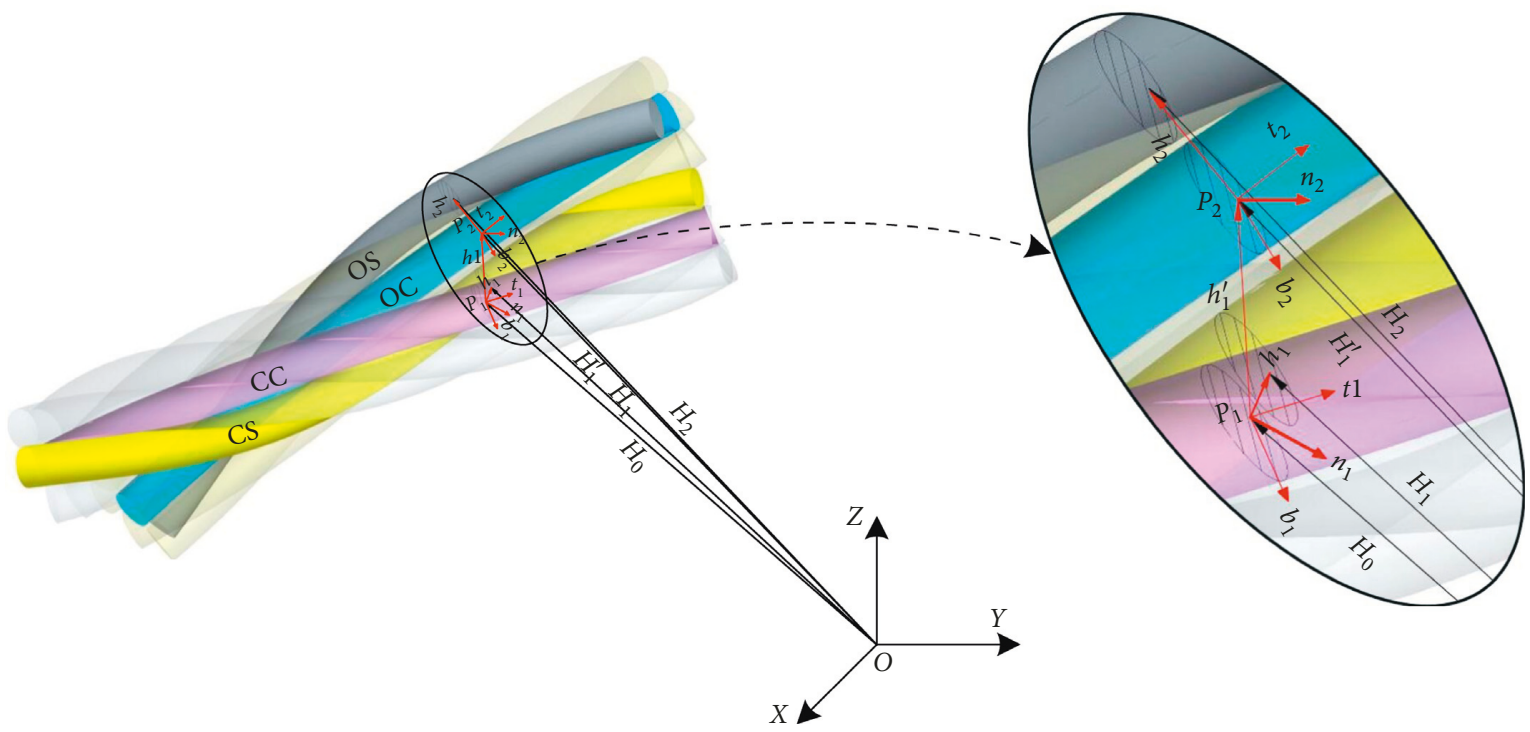

FIGURE 6: Use of the frame in the calculation of helix winding arc.

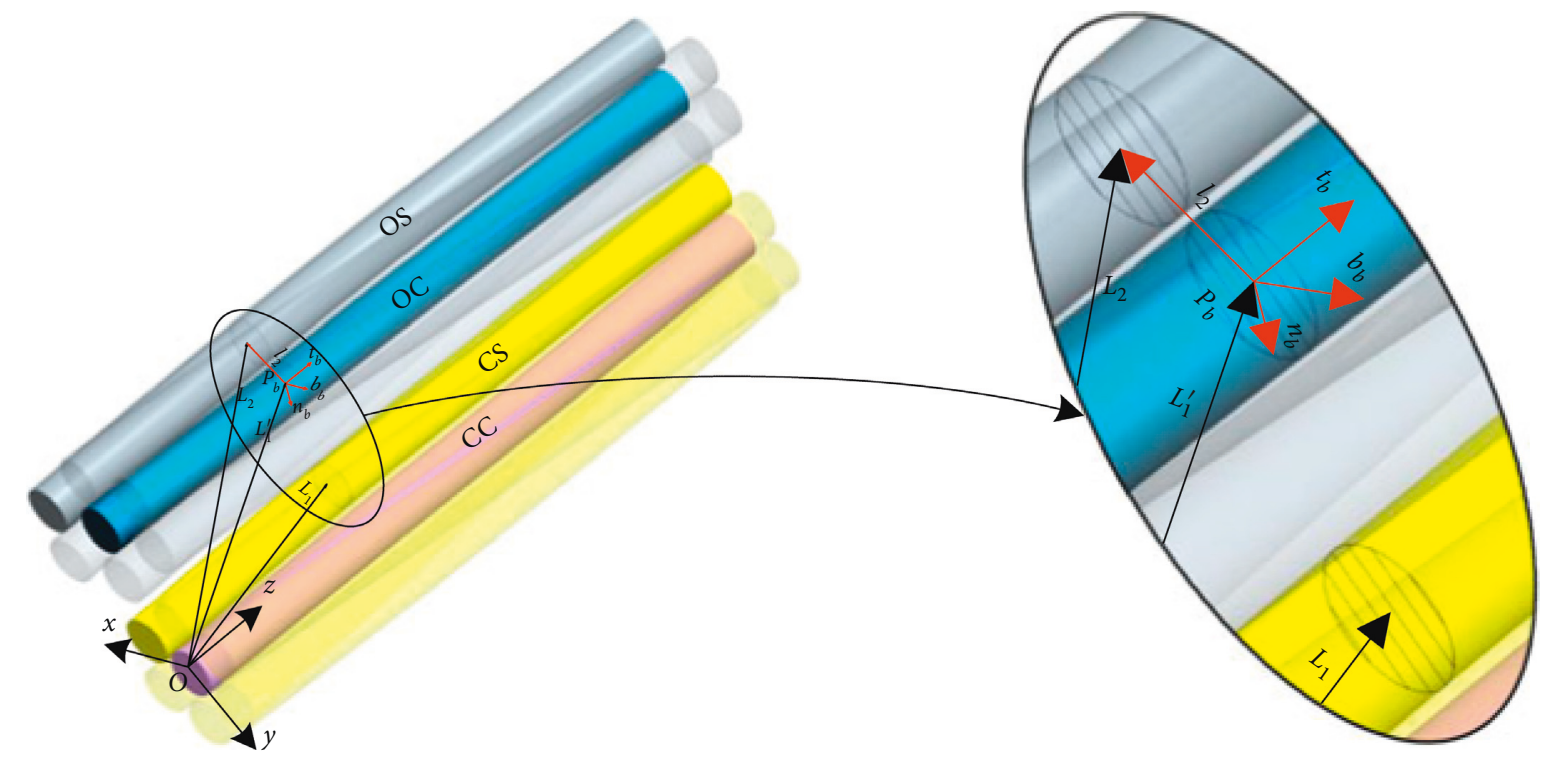

FIgURE 7: Use of the frame in the calculation of helix winding straight line.

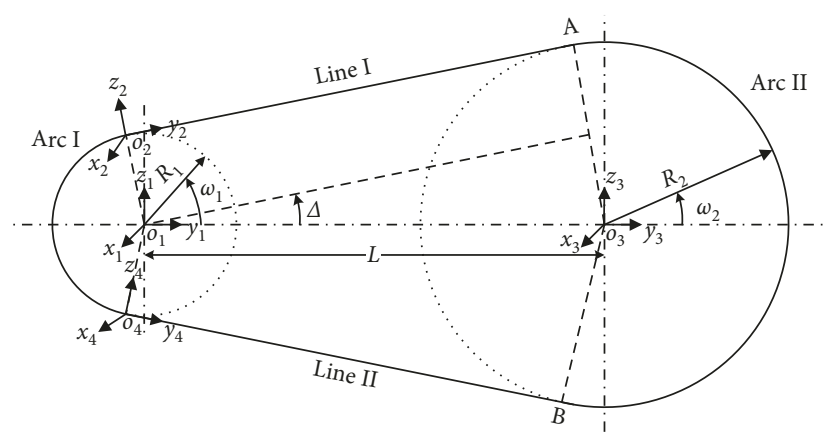

FIGURE 8: Coordinate systems at rope segments of no-joint wire rope.

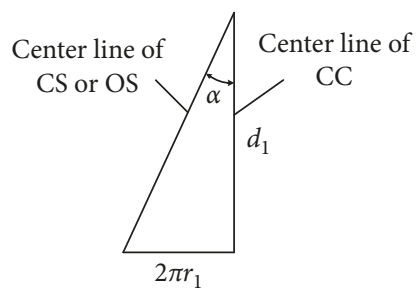

Figure 9: Winding of $\alpha$.

$$
\left\{\begin{array}{l}
x(t)=0, \\
y(t)=S_{2 n} t, \quad t \in[0,1] \\
z(t)=0 .
\end{array}\right.
$$




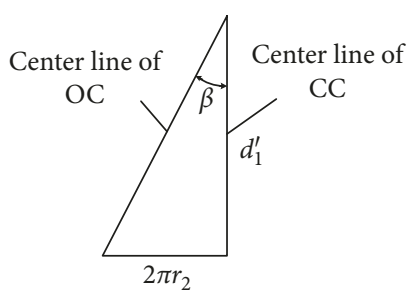

Figure 10: Winding of $\beta$.

4.3. Equations of Single Helix. Both CS and OC center lines are single helix. Because the equation of single-helix winding arc is different from that of winding line, it is deduced separately.

4.3.1. Equations of Single-Helix Winding Arc I and Arc II. Firstly, the frame $\mathbf{n}_{1}-\mathbf{b}_{1}-\mathbf{t}_{1}$ is established on the center line of CC in arc, calculated by equations (1) and (6).

For instance, equation (1) is used to calculate a response surface as follows:

$$
\left\{\begin{array}{l}
\mathbf{n}_{1}=\left(0,-\cos \omega_{n},-\sin \omega_{n}\right) \\
\mathbf{b}_{1}=(1,0,0) \\
\mathbf{t}_{1}=\left(0,-\sin \omega_{n}, \cos \omega_{n}\right)
\end{array}\right.
$$

Put the starting point of the center line of on the $\mathbf{b}_{1}$ axis, and rotate counterclockwise around $\mathbf{t}_{1}$ by $\theta_{1 n}$ degrees with radius $r_{1}$. Then, the vector $\mathbf{h}_{1}$ in the frame is obtained:

$$
\mathbf{h}_{1}=\left(-r_{1} \sin \left(\theta_{1 n}+\xi_{j}\right), r_{1} \cos \left(\theta_{1 n}+\xi_{j}\right), 0\right) \text {. }
$$

Taking $\mathbf{H}_{0}=\left(x\left(\omega_{n}\right), y\left(\omega_{n}\right), z\left(\omega_{n}\right)\right)$, equations (8) and (9) into equation (2), equations of center line of CS in Arc I and Arc II are obtained:

$$
\left\{\begin{array}{l}
x\left(\theta_{1 n}\right)=x\left(\omega_{n}\right)+r_{1} \cos \left(\theta_{1 n}+\xi_{j}\right), \\
y\left(\theta_{1 n}\right)=y\left(\omega_{n}\right)+r_{1} \sin \left(\theta_{1 n}+\xi_{j}\right) \cos \omega_{n}, \\
z\left(\theta_{1 n}\right)=z\left(\omega_{n}\right)+r_{1} \sin \left(\theta_{1 n}+\xi_{j}\right) \sin \omega_{n} .
\end{array}\right.
$$

The equation derivation process of central line of OC in arc is similar to CS, so the equation is directly listed as follows:

$$
\left\{\begin{array}{l}
x\left(\varphi_{1 n}\right)=x\left(\omega_{n}\right)+r_{2} \cos \left(\varphi_{1 n}+\eta_{i}\right) \\
y\left(\varphi_{1 n}\right)=y\left(\omega_{n}\right)+r_{2} \sin \left(\varphi_{1 n}+\eta_{i}\right) \cos \omega_{n} \\
z\left(\varphi_{1 n}\right)=z\left(\omega_{n}\right)+r_{2} \sin \left(\varphi_{1 n}+\eta_{i}\right) \sin \omega_{n}
\end{array}\right.
$$

4.3.2. Equations of Single-Helix Winding Line I and Line II. Single-helix winding line includes CS and OC, and their equations are simple and listed as follows:

$$
\begin{aligned}
& \left\{\begin{array}{l}
x\left(\theta_{2 n}\right)=r_{1} \cos \left(\theta_{2 n}+\xi_{j}\right), \\
y\left(\theta_{2 n}\right)=\left(\frac{r_{1}}{\tan \alpha}\right) \theta_{2 n}, \\
z\left(\theta_{2 n}\right)=-r_{1} \sin \left(\theta_{2 n}+\xi_{j}\right),
\end{array}\right. \\
& \left\{\begin{array}{l}
x\left(\varphi_{2 n}\right)=r_{2} \cos \left(\varphi_{2 n}+\eta_{i}\right), \\
y\left(\varphi_{2 n}\right)=\left(\frac{r_{2}}{\tan \beta}\right) \varphi_{2 n}, \\
z\left(\varphi_{2 n}\right)=-r_{2} \sin \left(\varphi_{2 n}+\eta_{i}\right) .
\end{array}\right.
\end{aligned}
$$

4.4. Equations of Double Helix. Only the center line of OS is double helix in the no-joint wire rope, because double helix equations of arc and straight line are not the same, so it needs to be deduced.

4.4.1. Double-Helix Equations of Arc I and Arc II. Establish the frame $\mathbf{n}_{2}-\mathbf{b}_{2}-\mathbf{t}_{2}$ on the central line of OC in the arc; this frame is calculated by equations (1) and (11):

$$
\left\{\begin{array}{l}
\mathbf{n}_{2}=\left(-\cos \left(\varphi_{1 n}+\eta_{i}\right),-\sin \left(\varphi_{1 n}+\eta_{i}\right) \cos \omega_{n},-\sin \left(\varphi_{1 n}+\eta_{i}\right) \sin \omega_{n}\right) \\
\mathbf{b}_{2}=\left(0,-\sin \omega_{n}, \cos \omega_{n}\right) \\
\mathbf{t}_{2}=\left(-\sin \left(\varphi_{1 n}+\eta_{i}\right), \cos \left(\varphi_{1 n}+\eta_{i}\right) \cos \omega_{n}, \cos \left(\varphi_{1 n}+\eta_{i}\right) \sin \omega_{n}\right)
\end{array}\right.
$$

The matrix $\mathbf{T}$ is used to make the angle between tangent of center line of OS and OC equal to $\beta$ :

$$
\mathbf{T}=\left[\begin{array}{ccc}
1 & 0 & 0 \\
0 & \sin \beta & -\cos \beta \\
0 & \cos \beta & \sin \beta
\end{array}\right]
$$

The starting point of center line of OS is located at $\mathbf{n}_{2}$ and rotates counterclockwise around $\mathbf{t}_{2}$ by $\psi_{1 n}$ degrees with radius $r_{1}$. Then, the vector $\mathbf{h}_{2}$ in the frame is obtained:

$$
\mathbf{h}_{2}=\left(-r_{1} \cos \left(\psi_{1 n}+\xi_{i j}\right), r_{1} \sin \left(\psi_{1 n}+\xi_{i j}\right), 0\right) \text {. }
$$

Taking $\mathbf{H}_{1}=\left(x\left(\varphi_{1 n}\right), y\left(\varphi_{1 n}\right), z\left(\varphi_{1 n}\right)\right)$ and substituting equations (14), (15), and (16) into equation (3), equations of center line of OS in Arc I and Arc II are obtained: 
TABLE 1: Parameters of right-hand Lang's lay NJ-6 $\times 7+$ IWS.

\begin{tabular}{lcc}
\hline Parameter symbol & Value & Unit \\
\hline$R_{1}$ & 10 & $\mathrm{~mm}$ \\
$R_{2}$ & 20 & $\mathrm{~mm}$ \\
$L$ & 50 & $\mathrm{~mm}$ \\
$r$ & 0.1 & $\mathrm{~mm}$ \\
$r_{1}$ & 0.22 & $\mathrm{~mm}$ \\
$r_{2}$ & 0.66 & $\mathrm{~mm}$ \\
$\alpha$ & 12.41 & $\circ$ \\
$\beta$ & 18.26 & $\circ$ \\
\hline
\end{tabular}

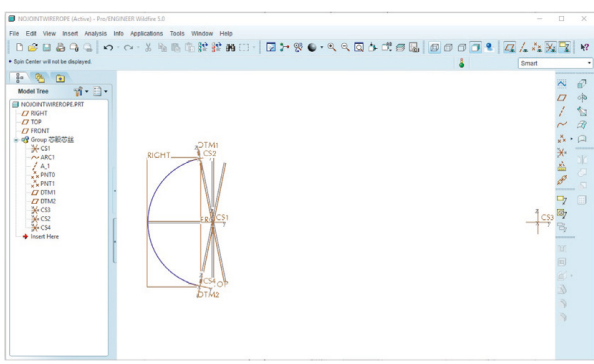

FIGURE 11: Setup for the coordinate systems.

$$
\left\{\begin{array}{l}
x\left(\psi_{1 n}\right)=x\left(\varphi_{1 n}\right)+r_{2}\left[\cos \left(\psi_{1 n}+\xi_{i j}\right) \cos \left(\varphi_{1 n}+\eta_{i}\right)-\sin \left(\psi_{1 n}+\xi_{i j}\right) \sin \left(\varphi_{1 n}+\eta_{i}\right) \cos \beta\right] \\
y\left(\psi_{1 n}\right)=y\left(\varphi_{1 n}\right)+r_{2} \sin \left(\psi_{1 n}+\xi_{i j}\right)\left[\sin \beta \sin \omega_{n}+\cos \left(\varphi_{1 n}+\eta_{i}\right) \cos \beta \cos \omega_{n}\right]+r_{2} \cos \left(\psi_{1 n}+\xi_{i j}\right) \sin \left(\varphi_{1 n}+\eta_{i}\right) \cos \omega_{n} \\
z\left(\psi_{1 n}\right)=z\left(\varphi_{1 n}\right)+r_{2} \sin \left(\psi_{1 n}+\xi_{i j}\right)\left[-\sin \beta \sin \omega_{n}+\cos \left(\varphi_{1 n}+\eta_{i}\right) \cos \beta \sin \omega_{n}\right]+r_{2} \cos \left(\psi_{1 n}+\xi_{i j}\right) \sin \left(\varphi_{1 n}+\eta_{i}\right) \sin \omega_{n}
\end{array}\right.
$$

4.4.2. Double-Helix Equations of Line I and Line II. Establish the frame $\mathbf{n}_{\mathrm{b}}-\mathbf{b}_{\mathrm{b}}-\mathbf{t}_{\mathrm{b}}$, which is calculated by equations (1) and (13), on the center line of OC in the Line I and Line II:

$$
\left\{\begin{array}{l}
\mathbf{n}_{\mathrm{b}}=\left(-\cos \left(\varphi_{2 n}+\eta_{i}\right), 0, \sin \left(\varphi_{2 n}+\eta_{i}\right)\right) \\
\mathbf{b}_{\mathrm{b}}=\left(\cos \beta \sin \left(\varphi_{2 n}+\eta_{i}\right), \sin \beta, \cos \beta \cos \left(\varphi_{2 n}+\eta_{i}\right)\right) \\
\mathbf{t}_{\mathrm{b}}=\left(-\sin \beta \sin \left(\varphi_{2 n}+\eta_{i}\right), \cos \beta,-\sin \beta \cos \left(\varphi_{2 n}+\eta_{i}\right)\right)
\end{array}\right.
$$

The starting point of the center line of OS is located at $\mathbf{n}_{\mathrm{b}}$, and it rotates clockwise around $\mathbf{t}_{\mathrm{b}}$ by $\psi_{2 n}$ degrees with radius $r_{1}$. Then, the vector $\mathbf{l}_{2}$ in the frame is obtained:

$$
\mathbf{l}_{2}=\left(-r_{1} \cos \left(\psi_{2 n}+\xi_{i j}\right), r_{1} \sin \left(\psi_{2 n}+\xi_{i j}\right), 0\right) \text {. }
$$

Taking $\mathbf{L}_{1}^{\prime}=\left(x\left(\varphi_{2 n}\right), y\left(\varphi_{2 n}\right), z\left(\varphi_{2 n}\right)\right)$, equations (18) and (19) into equation (4), equations of center line of OS in Line I and Line II are obtained:

$$
\left\{\begin{array}{l}
x\left(\psi_{2 n}\right)=x\left(\varphi_{2 n}\right)+r_{1}\left[\cos \left(\psi_{2 n}+\xi_{i j}\right) \cos \left(\varphi_{2 n}+\eta_{i}\right)+\sin \left(\psi_{2 n}+\xi_{i j}\right) \sin \left(\varphi_{2 n}+\eta_{i}\right) \cos \beta\right], \\
y\left(\psi_{2 n}\right)=y\left(\varphi_{2 n}\right)+r_{1} \sin \left(\psi_{2 n}+\xi_{i j}\right) \sin \beta \\
z\left(\psi_{2 n}\right)=z\left(\varphi_{2 n}\right)+r_{1}\left[-\cos \left(\psi_{2 n}+\xi_{i j}\right) \sin \left(\varphi_{2 n}+\eta_{i}\right)+\sin \left(\psi_{2 n}+\xi_{i j}\right) \cos \left(\varphi_{2 n}+\eta_{i}\right) \cos \beta\right] .
\end{array}\right.
$$

\section{Generate 3D Solid Model of NJ-6 × $7+$ IWS}

5.1. Parameters of NJ-6 $\times 7+I W S$. Table 1 shows the parameters of right-hand Lang's lay NJ-6 $67+$ IWS, on which $3 \mathrm{D}$ modeling is mainly based.

5.2. Generation of 3D Solid Model. The modeling software used in this paper is Pro/ENGINEER Wildfire 5.0, and the solid model of the no-joint wire rope is established according to the preceding equations.

Firstly, the coordinate systems are established according to the tangent condition, and the center line of CC in Arc I is used as the reference. The result is obtained by using reference coordinate, datum, reference axis, and more, as shown in Figure 11.

Secondly, generate the solid model of the center strand, which is composed of CC solid model and CS solid model. The generation process of CC solid model is shown in Figure 12, in which Panels (1) to (3) show the generation process of center line of CC. Panel (4) is the CC solid model, and small graphs in Panel (4) are the magnification of junction between line and arc. This expression method in the subsequent diagram is the same as here.

The generation step of the CS solid model is shown in Figure 13; Panels (1) to (4) show the generation process of the center line of $\mathrm{CS}_{1}$. Other generation processes of center line of CS are similar to $\mathrm{CS}_{1}$, and their generation results are shown in Panel (5). Then, generate the solid model of CS, in which Panel (6) is $\mathrm{CS}_{1}$ for the solid model. Generation processes from $\mathrm{CS}_{2}$ to $\mathrm{CS}_{6}$ are similar to Panel (6), and the results are shown in Panel (7). At the same time, the solid model of the center strand is also completed.

Finally, generate the solid models of side strand as shown in Figure 14. Take one side strand as an example to show. Panels (1) to (4) show the generation process of the center line of $\mathrm{OC}_{11}$, and Panel (5) is the $\mathrm{OC}_{11}$ solid model. Panel (6) shows the generation result of the center line from $\mathrm{OS}_{11}$ to $\mathrm{OS}_{16}$, Panel (7) is the solid model from $\mathrm{OS}_{11}$ to $\mathrm{OS}_{16}$, and a solid model of one side strand is also established at the same 


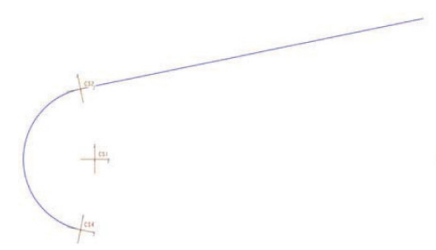

(1)

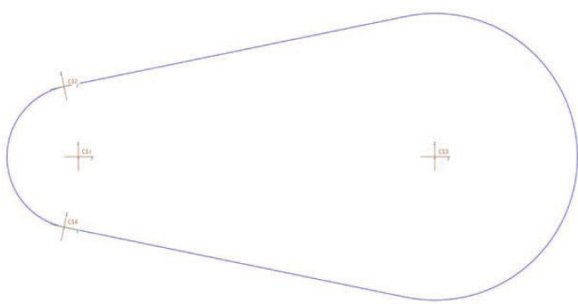

(3)

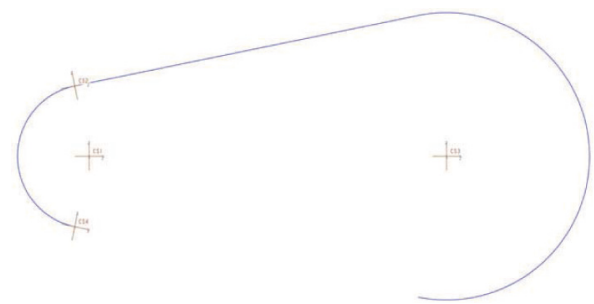

(2)

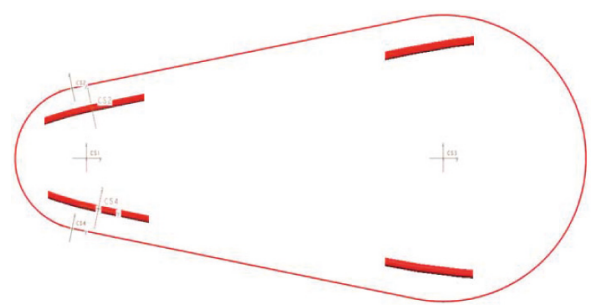

(4)

FIGURE 12: Generation process of the CC solid model.

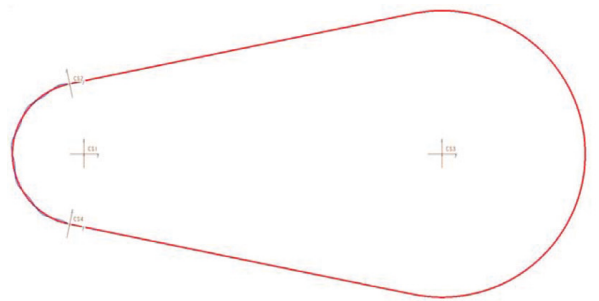

(1)

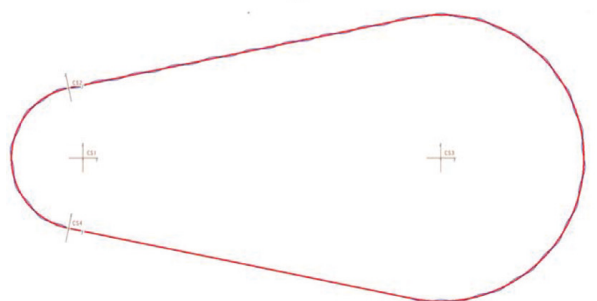

(3)

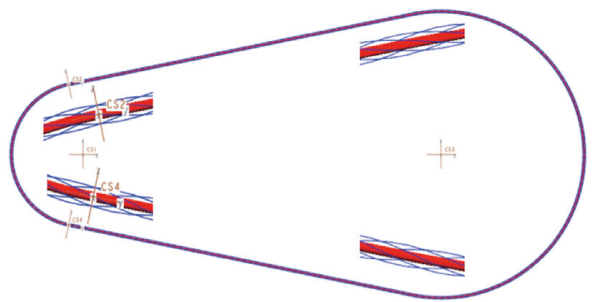

(5)

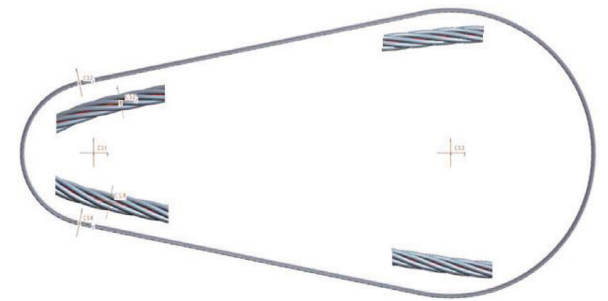

(7)

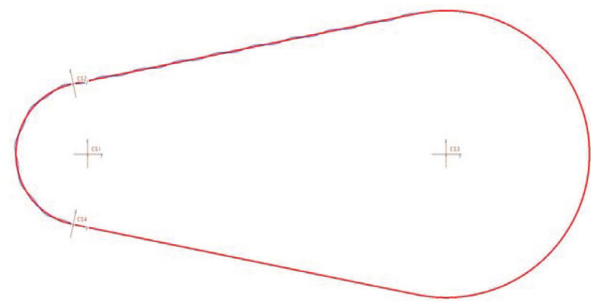

(2)

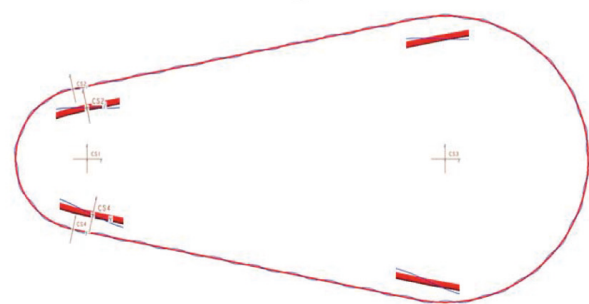

(4)

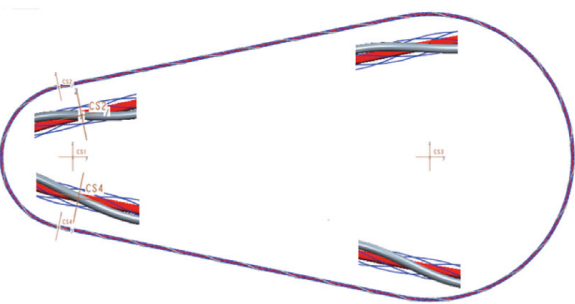

(6)

FIgURE 13: Generation process of the solid model of CS. 


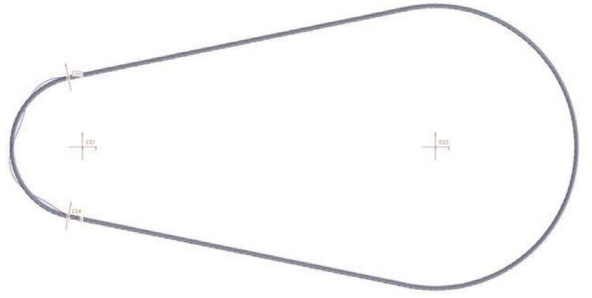

(1)

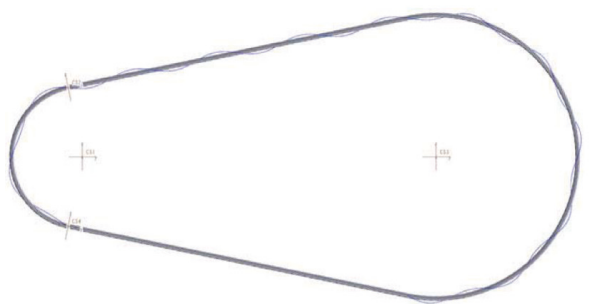

(3)

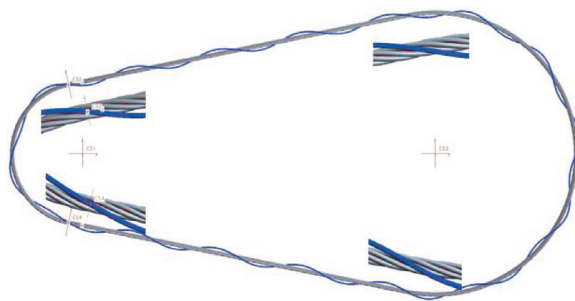

(5)

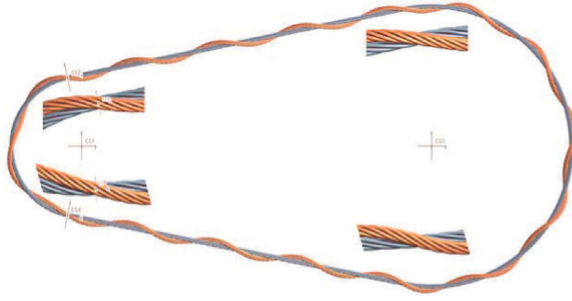

(7)

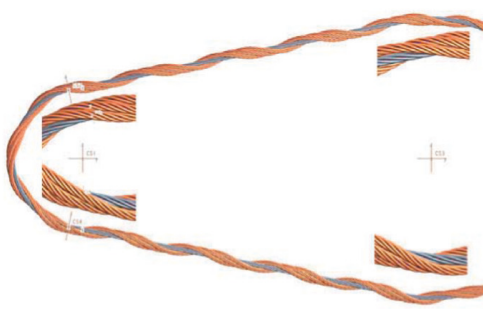

(9)

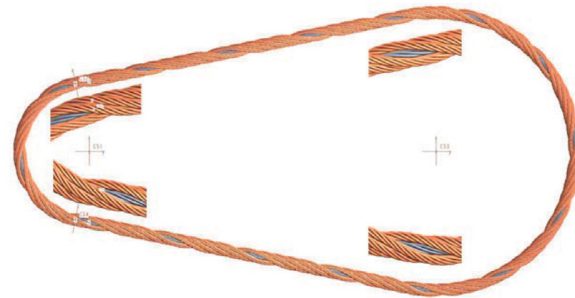

(11)

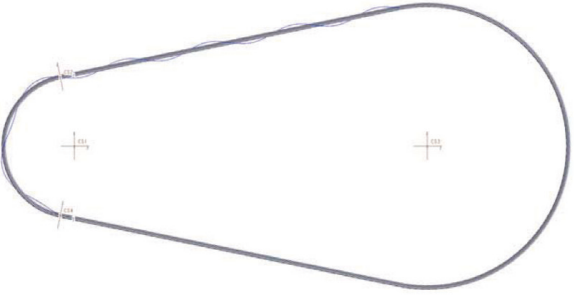

(2)

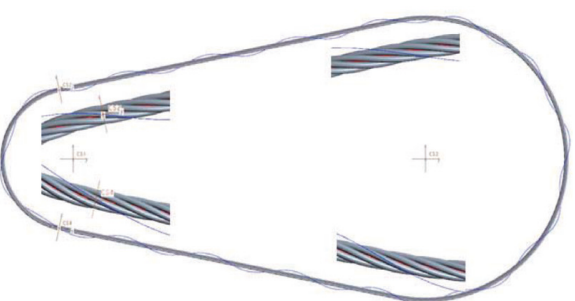

(4)

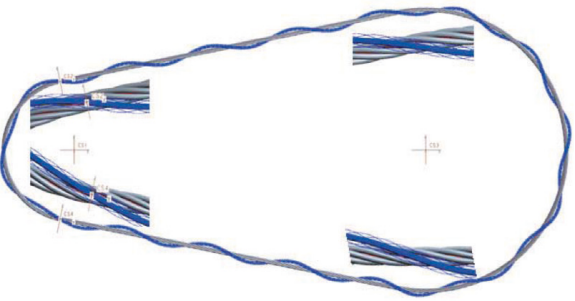

(6)

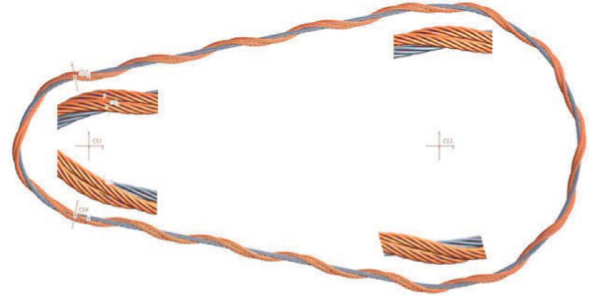

(8)

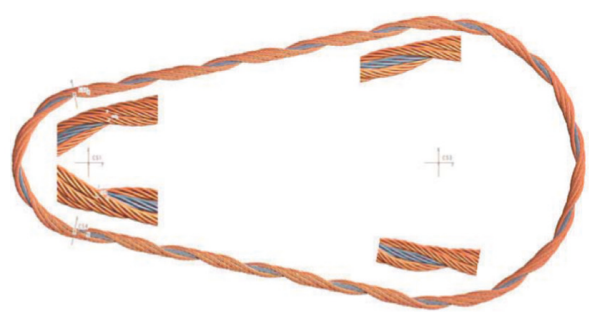

(10)

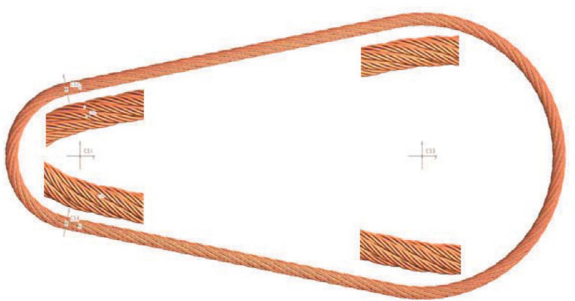

(12)

Figure 14: Generation process of the solid model of side strand. 


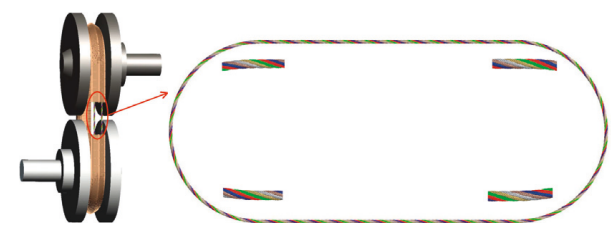

FIGURE 15: WR-CVT and no-joint wire rope when the transmission ratio is 1 .

time. The generation process of other side strands is similar to one side strand, so we only show the generation results. Panels (8) to (12) show the solid model from two side strands to six side strands, and the solid model of no-joint wire rope is also established at the same time.

If the wire rope parameter value is changed, the no-joint wire rope, which is used in WR-CVT, can be built when the transmission ratio is 1 , as shown in Figure 15.

\section{Conclusions}

This paper, taking a basic form of belt transmission as the background, establishes a no-joint wire rope model and mainly studies the geometric modeling method of no-joint wire rope, which consists of two straight lines and two arcs, as well as the implementation of a 3D solid model. The main conclusions are as follows.

Based on the cross section of $6 \times 7+$ IWS wire rope, this study analyzes the geometrical relationship among various kinds of wires and set up three kinds of Frenet-Serret frame, which are on the double-helix winding straight line, singlehelix winding arc, and double-helix winding arc, combined with Frenet-Serret frame theory, and derives four types of equations when wire rope segments are straight lines and arcs. The tangent condition has been obtained where the direction of the center line of same numbered wire must be tangent and the closed condition where the length of wire must be an integer multiple of its lay pitch, and the wire's number must be the same. Finally, using Pro/E software generates two typical shapes of the no-joint wire rope $3 \mathrm{D}$ solid model when the transmission ratio of WR-CVT is 1 and is not 1 . This paper further improves the geometric modeling system of wire rope and lays a theoretical foundation for the mechanical and dynamic analyses of no-joint wire rope.

\section{Nomenclature}

WR-CVT: Wire rope-continuously variable transmission $6 \times 7+$ IWS: “ 6 " indicates number of strand, " 7 " indicates number of wire in every strand, and "IWS" indicates core strand is steel core

NJ- No-joint wire rope with cross section of

$6 \times 7+$ IWS: $6 \times 7+$ IWS

CC: $\quad$ Core strand center wire

$\mathrm{CS}_{j}$ : $\quad \mathrm{CS}$ indicates core strand side wire, “ $j$ " is wire number, $j=1,2, \ldots, 6$

$\mathrm{OC}_{i}$ : $\quad$ OC indicates outer strand center wire, " $i$ " is strand number, $i=1,2, \ldots, 6$

$\mathrm{OS}_{i j}$ : $\quad$ OS indicates outer strand side wire, " $i$ " and " $j$ " have the same meaning as above
$(O: x, y, z):$ Cartesian coordinate system

$\left(O_{1}: x_{1}, y_{1}\right.$, Cartesian coordinate system at center of CC of

$\left.z_{1}\right)$ : arc I

$\left(\mathrm{O}_{2}: x_{2}, y_{2}\right.$, Cartesian coordinate system at left end point of

$\left.z_{2}\right): \quad$ CC of line I

$\left(\mathrm{O}_{3}: x_{3}, y_{3}\right.$, Cartesian coordinate system at center of CC of $\left.z_{3}\right): \quad$ arc II

$\left(\mathrm{O}_{4}: x_{4}, y_{4}\right.$, Cartesian coordinate system at left end point of $\left.z_{4}\right):$

$\mathbf{h}(\gamma)$ :

$\mathbf{N}$ :

B:

T:

n:

b:

t:

$\mathbf{n}-\mathbf{b}-\mathbf{t}$ :

$\mathbf{n}_{1}-\mathbf{b}_{1}-\mathbf{t}_{1}$ :

$\mathbf{n}_{2}-\mathbf{b}_{2}-\mathbf{t}_{2}$ :

$\mathbf{n}_{\mathrm{b}}-\mathbf{b}_{\mathrm{b}}-\mathbf{t}_{\mathrm{b}}$ :

CC of line II

Vector representation of space curve $\mathbf{h}(\gamma)$

Normal vector of curve $\mathbf{h}(\gamma)$

Binormal vector of curve $\mathbf{h}(\gamma)$

Tangent vector of curve $\mathbf{h}(\boldsymbol{\gamma})$

Unit normal vector of curve $\mathbf{h}(\gamma)$

Unit binormal vector of curve $\mathbf{h}(\gamma)$

Unit tangent vector of curve $\mathbf{h}(\gamma)$

Frenet-Serret frame

Frenet-Serret frame on center line of CC of arc

Frenet-Serret frame on center line of OC of arc

Frenet-Serret frame on center line of OC of line

$\mathbf{H}_{0}$ : The vector of center line of CC of arc in the Cartesian coordinate system

$\mathbf{H}_{1}$ : The vector of center line of CS of arc in the Cartesian coordinate system

$\mathbf{H}_{1}^{\prime}$ : $\quad$ The vector of center line of OC of arc in the Cartesian coordinate system

$\mathbf{H}_{2}$ : The vector of center line of OS of arc in the Cartesian coordinate system

$\mathbf{h}_{1}$ : The vector of center line of CS of arc in $\mathbf{n}_{1}-\mathbf{b}_{1}-\mathbf{t}_{1}$

$\mathbf{h}_{1}^{\prime}$ : $\quad$ The vector of center line of OC of arc in $\mathbf{n}_{1}-\mathbf{b}_{1}-\mathbf{t}_{1}$

$\mathbf{h}_{2}$ : The vector of center line of OS of arc in $\mathbf{n}_{2}-\mathbf{b}_{2}-\mathbf{t}_{2}$

$\mathbf{L}_{1}$ : $\quad$ The vector of center line of CS of arc in the Cartesian coordinate system

$\mathbf{L}_{1}^{\prime}$ : $\quad$ The vector of center line of OC of arc in the Cartesian coordinate system

$\mathbf{L}_{2}$ : $\quad$ The vector of center line of OS of arc in the Cartesian coordinate system

$\mathbf{1}_{2}$ : The vector of center line of OS of line in $\mathbf{n}_{\mathrm{b}}-\mathbf{b}_{\mathrm{b}}-\mathbf{t}_{\mathrm{b}}$

T:

$\eta_{i}:$

$\xi_{j}:$

$\xi_{i j}:$

$\alpha:$

$\beta:$

$d_{1}$ :

$d_{1}^{\prime}$ :

$S_{m n}$ :

Coordinate transformation matrix

$\mathrm{OC}_{i}$ initial phase, $\eta_{i}=(i-1) 60^{\circ}\left({ }^{\circ}\right)$

$\mathrm{CS}_{j}$ initial phase, $\xi_{j}=(j-1) 60^{\circ}\left({ }^{\circ}\right)$

$\mathrm{OS}_{i j}$ initial phase, $\xi_{i j}=(j-1) 60^{\circ}\left({ }^{\circ}\right)$

Helix angle of strand $\left({ }^{\circ}\right)$

Helix angle of wire rope $\left({ }^{\circ}\right)$

Lay pitch of strand ( $\mathrm{mm}$ )

Lay pitch of wire rope $(\mathrm{mm})$

$S$ indicates length of center line of wire rope segment; $m$ indicates shape of wire rope when " $m=1$ " is arc and " $m=2$ " is line; $n$ is the number of wire rope segment, $n=1,2(\mathrm{~mm})$

$\omega_{m n}:$

$\theta_{m n}$ :

$\varphi_{m n}:$
Rotation angle of center line of CC of arc $\left(^{\circ}\right)$

Winding angle of CS $\left(^{\circ}\right)$

Winding angle of OC $\left({ }^{\circ}\right)$ 


$\begin{array}{ll}\psi_{m n}: & \text { Winding angle of OS }\left(^{\circ}\right) \\ \Delta: & \text { Included angle between the line segment and } \\ & \text { symmetric line }\left(^{\circ}\right) \\ L: & \text { The length between the center of arc I and arc } \\ & \text { II (mm) } \\ R_{n}: & \text { Radius of arc, } n=1,2(\mathrm{~mm}) \\ r: & \text { Radius of cross section of wire }(\mathrm{mm}) \\ r_{1}: & \text { Helical radius of center line of side wire }(\mathrm{mm}) \\ r_{2}: & \text { Helical radius of center line of OC }(\mathrm{mm}) .\end{array}$

\section{Data Availability}

The data used to support the findings of this study are available from the corresponding author upon request.

\section{Conflicts of Interest}

The authors declare that they have no conflicts of interest.

\section{Acknowledgments}

This research was supported by the Outstanding Youth Science Fund of Xi'an University of Science and Technology (Grant no. 2019YQ2-12), Shanxi Key Research and Development Program (Grant no. 2018GY-163), the National Natural Science Foundation of China (Grant no. 51905418), Shaanxi Natural Science Fundamental Research Program Enterprise Joint Fund Project (Grant no. 2019JLM-37), and the State Key Laboratory of Mechanical Transmissions Open Fund (SKLMT-KFKT-201810). The authors are grateful for the support.

\section{References}

[1] W. Zhang, C. Zhang, W. Guo, X. Xu, and Z. Lu, "Research on modeling and bending stress distribution of a new metal belt continuously variable transmission," Mechanism and Machine Theory, vol. 116, pp. 220-233, 2017.

[2] E. Stanova, G. Fedorko, M. Fabian, and S. Kmet, "Computer modelling of wire strands and ropes Part I: theory and computer implementation," Advances in Engineering Software, vol. 42, no. 6, pp. 305-315, 2011.

[3] W. K. Lee, N. F. Casey, and T. G. Gray, "Helix geometry in wire rope," Wire Industry, vol. 54, no. 644, pp. 461-468, 1987.

[4] W. K. Lee, "An insight into wire rope geometry," International Journal of Solids and Structures, vol. 28, no. 4, pp. 471-490, 1991.

[5] X.-Y. Wang, X.-B. Meng, J.-X. Wang, Y.-H. Sun, and K. Gao, "Mathematical modeling and geometric analysis for wire rope strands," Applied Mathematical Modelling, vol. 39, no. 3-4, pp. 1019-1032, 2015.

[6] A. Nawrocki and M. Labrosse, "A finite element model for simple straight wire rope strands," Computers \& Structures, vol. 77, no. 4, pp. 345-359, 2000.

[7] R. Judge, Z. Yang, S. W. Jones, and G. Beattie, "Full 3D finite element modelling of spiral strand cables," Construction and Building Materials, vol. 35, pp. 452-459, 2012.

[8] C. Erdonmez and C. E. Imrak, "A finite element model for independent wire rope core with double helical geometry subjected to axial loads," Sadhana, vol. 36, no. 6, pp. 9951008, 2011.
[9] C. Erdönmez, " $n$-tuple complex helical geometry modeling using parametric equations," Engineering with Computers, vol. 30, no. 4, pp. 715-726, 2014.

[10] E. Stanová, "Geometry and modeling of the oval strand of $n_{0}+\left(2 n_{0}+4\right)+n_{2}$ type," Selected Scientific Papers-Journal of Civil Engineering, vol. 7, no. 2, pp. 33-40, 2012.

[11] G. Fedorko, E. Stanova, V. Molnar, N. Husakova, and S. Kmet, "Computer modelling and finite element analysis of spiral triangular strands," Advances in Engineering Software, vol. 73, pp. 11-21, 2014.

[12] W. Ma, Y. X. Zhu, and G. A. Chen, "Computer-aided modeling of wire ropes bent over a sheave," Advances in Engineering Software, vol. 90, pp. 11-21, 2015.

[13] J. Wu, K. Zi-Ming, L. Yu-Hui et al., "Numerical simulation of stress-strain of bended wire rope," Journal of China Coal Society, vol. 40, no. 6, pp. 1463-1468, 2015.

[14] Y.-X. Peng, X.-D. Chang, S.-S. Sun et al., "The friction and wear properties of steel wire rope sliding against itself under impact load," Wear, vol. 400-401, pp. 194-206, 2018.

[15] W. Zhou and H.-Q. Tian, "A novel finite element model for single-layered wire strand," Journal of Central South University, vol. 20, no. 6, pp. 1767-1771, 2013.

[16] E. Stanova, G. Fedorko, M. Fabian, and S. Kmet, "Computer modelling of wire strands and ropes part II: finite elementbased applications," Advances in Engineering Software, vol. 42, no. 6, pp. 322-331, 2011.

[17] D. Elata, R. Eshkenazy, and M. P. Weiss, "The mechanical behavior of a wire rope with an independent wire rope core," International Journal of Solids and Structures, vol. 41, no. 5-6, pp. 1157-1172, 2004.

[18] I. Páczelt and R. Beleznai, "Nonlinear contact-theory for analysis of wire rope strand using high-order approximation in the FEM," Computers and Structures, vol. 89, no. 11-12, pp. 1004-1025, 2011.

[19] A. Cruzado, M. A. Urchegui, and X. Gómez, "Finite element modeling and experimental validation of fretting wear scars in thin steel wires," Wear, vol. 289, pp. 26-38, 2012.

[20] A. Cruzado, M. A. Urchegui, and X. Gómez, "Finite element modeling of fretting wear scars in the thin steel wires: application in crossed cylinder arrangements," Wear, vol. 318, no. 1-2, pp. 98-105, 2014.

[21] D. Wang, D. Zhang, S. Wang, and S. Ge, "Finite element analysis of hoisting rope and fretting wear evolution and fatigue life estimation of steel wires," Engineering Failure Analysis, vol. 27, pp. 173-193, 2013.

[22] B. D. Leonard, F. Sadeghi, S. Shinde, and M. Mittelbach, "A numerical and experimental investigation of fretting wear and a new procedure for fretting wear maps," Tribology Transactions, vol. 55, no. 3, pp. 313-324, 2012. 


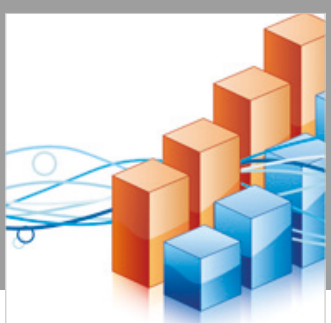

Advances in

Operations Research

\section{-n-m}
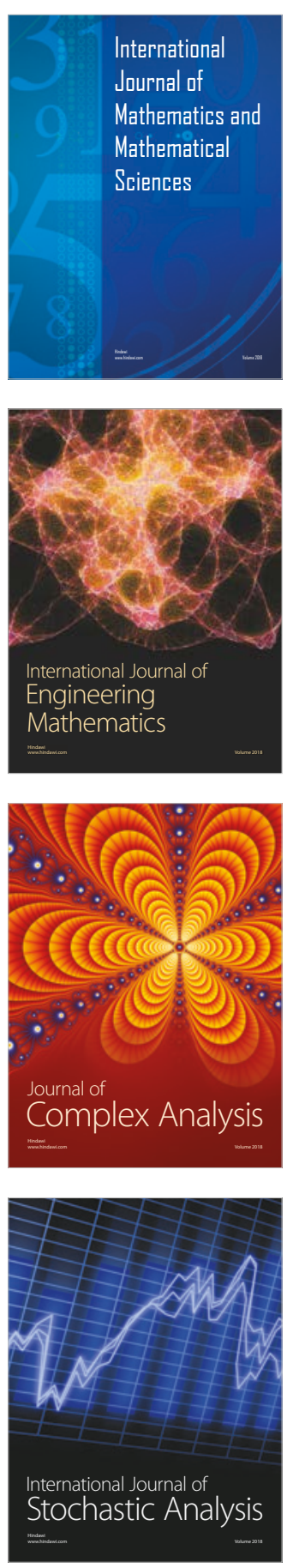
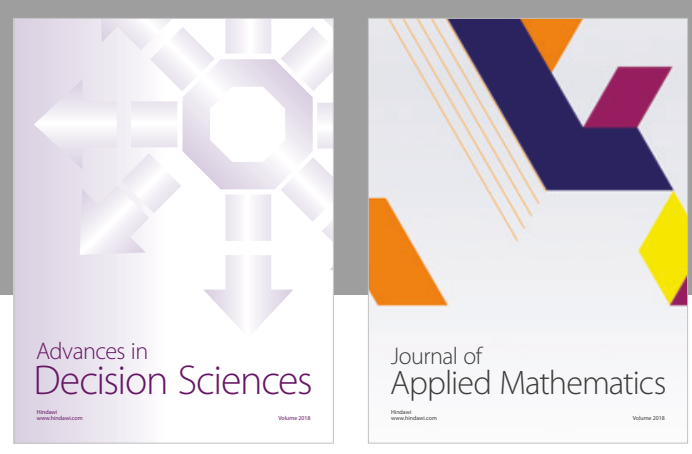

Journal of

Applied Mathematics
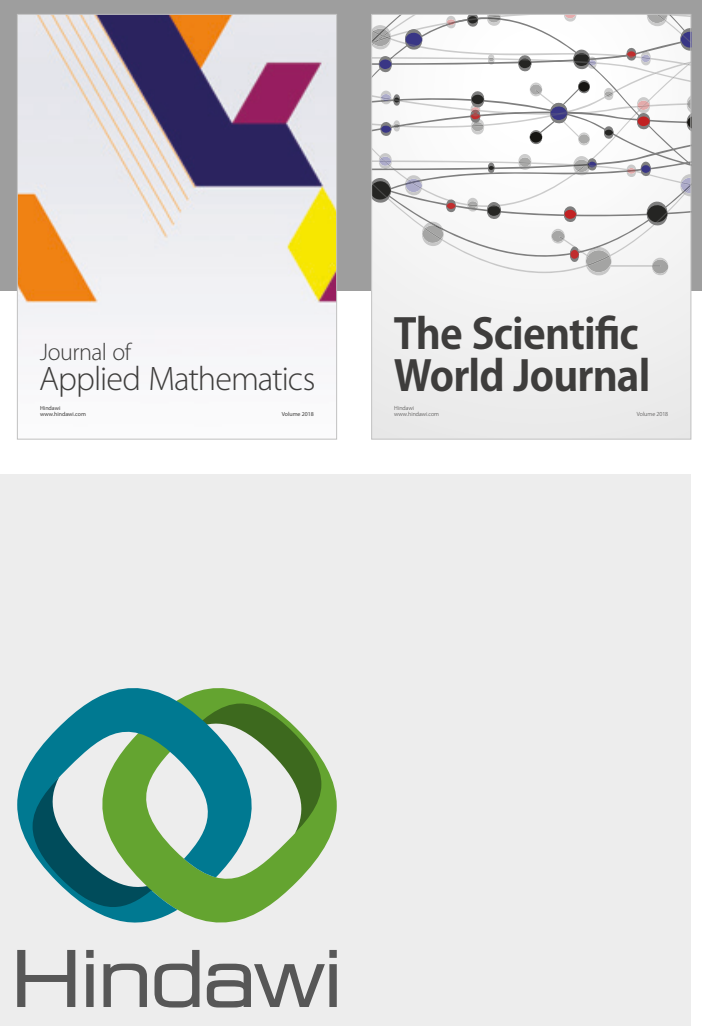

Submit your manuscripts at

www.hindawi.com

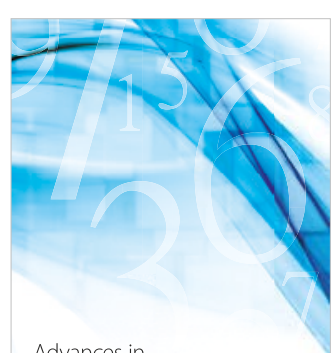

Advances in
Numerical Analysis
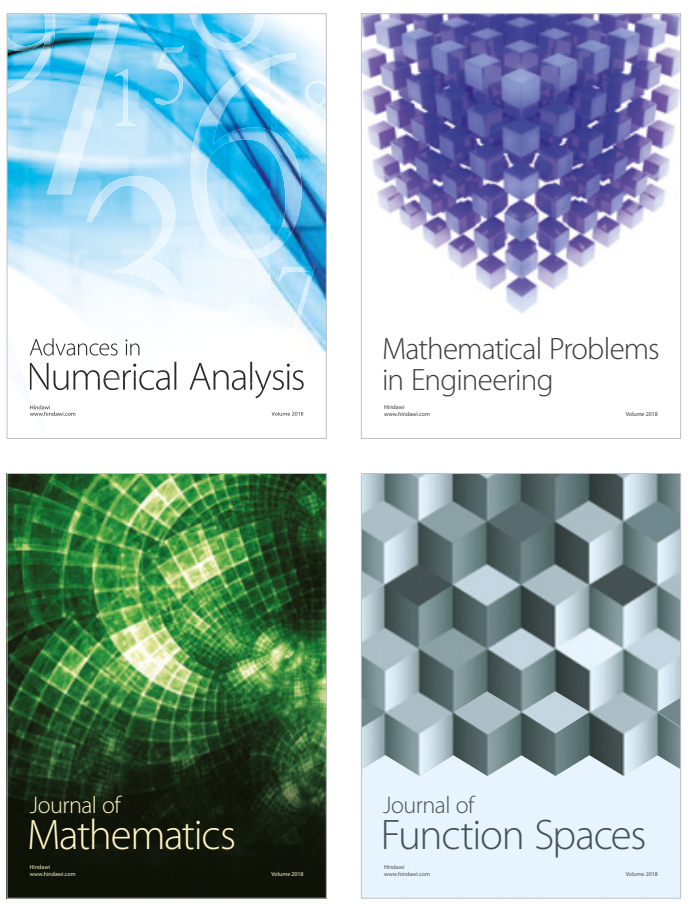

Mathematical Problems in Engineering

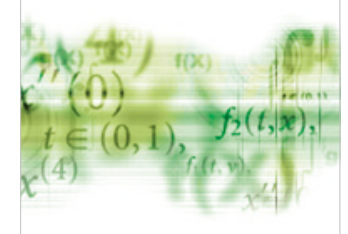

International Journal of

Differential Equations

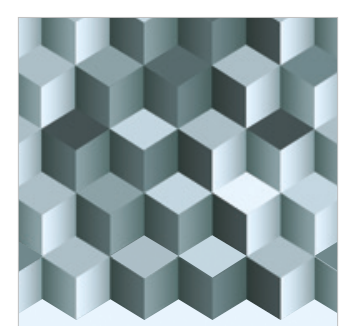

Journal of

Function Spaces
The Scientific

World Journal

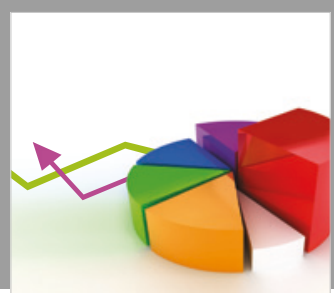

Journal of

Probability and Statistics
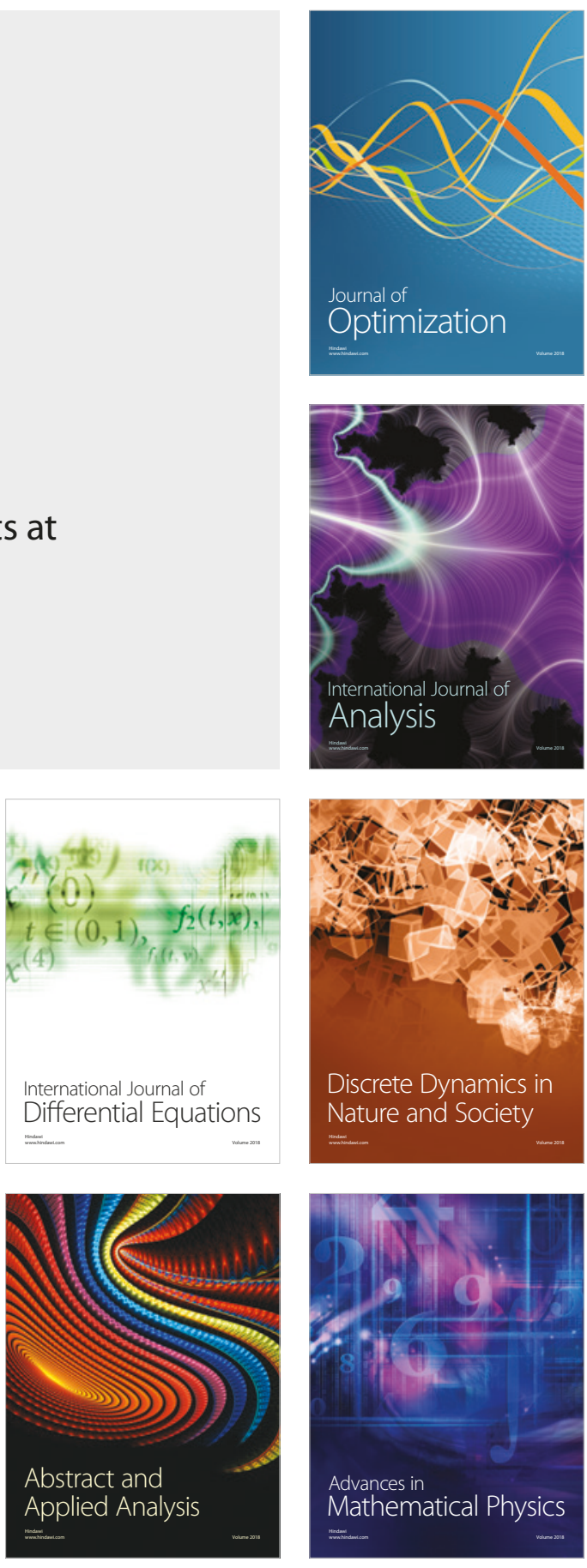